\title{
INTERDISCIPLINARY AND CROSS-CULTURAL LITERACY: AN ACTIVITY INCREASING BUSINESS AND NURSING STUDENTS CULTURAL AND HEALTH CARE INDUSTRY AWARENESS
}

\author{
FLORRIANN FEHR, PAUL CLARK, MICHELLE FUNK
}

\begin{abstract}
:
This article describes an experiential learning assignment encompassing an activity used by three faculty members in two different academic disciplines, Nursing and International Business. This assignment has proven to be mutually beneficial for students and teachers in achieving their course learning objectives. This assignment can be used as a template for other instructors interested in cross cultural and / or cross disciplinary collaboration.

In its current form, this assignment involves a 300 level course for students studying International Business and a 200 level course for nursing students studying Relational Practice and communication with others. The activity concerns the assigning of students into small working groups whose members are representative of different cultures and different academic disciplines. This mission requires students to meet (out of regular class time) to discuss and share their knowledge and perceptions of their own culture and the health care industry in their home countries.

Students may participate in this activity regardless of their level of knowledge regarding the other's culture. Participating in the activity provides students the opportunity to discuss characteristics of their own culture and country and to learn about other countries from fellow students. The activity encourages break downs in stereotyping, and to generate confidence in communicating with others that may seem 'different'.
\end{abstract}

\section{Keywords:}

Experiential Learning, Active Learning, Cultural Sensitivity, Cultural Awareness, Communication, English as a Second Language, Health Care Industry, International Business, Cultural Literacy

JEL Classification: A12, I12, 057

\section{Authors:}

FLORRIANN FEHR, Thompson Rivers University, Canada, Email: ffehr@tru.ca

PAUL CLARK , Thompson Rivers University, Canada, Email: Ffehr@tru.ca

MICHELLE FUNK, Thompson Rivers University , Canada, Email: mfunk@tru.ca

\section{Citation:}

FLORRIANN FEHR, PAUL CLARK, MICHELLE FUNK (2019). Interdisciplinary and Cross-Cultural Literacy: An Activity Increasing Business and Nursing Students Cultural and Health Care Industry 
Awareness. International Journal of Teaching and Education, Vol. VII(1), pp. 41-55.,

10.20472/TE.2019.7.1.004 


\section{Introduction}

Canadian campuses contain of a wealth of knowledge, with many opportunities for reciprocal culturally diverse learning experiences. Higher education years are the best times to prepare students for the demands of an ever diverse global society (Jayakumar, 2008). Educators have the opportunity to facilitate intercultural and cross-disciplinary learning without having to leave campus. Learning together by mixing different higher education discipline learning activities is not new, many global educators have shared strategies to impact peer learning through interaction related activities (Allen, 2010; Hou \& McDowell, 2013).

New curriculum delivery models supporting interdisciplinary learning are suggested to take advantage of collaborative opportunities on an ever diverse campus environment. Mixing different cultures, different disciplines, and exploring diverse ways to communicate can be a source of enrichment and a challenging adjustment experience for higher education students. Internationalization strategies are a component of cross-cultural campuses, and learning activities comprising different disciplinary lens might be a way to invoke student encounters in developing new and raised perspectives of different linguistic and cultural knowledge. By using common group identity and mutual learning goals, exploration and raised intercultural competence is achievable while on campus.

According to American nurse educators, Bednarz, Schim and Doorenbos (2010), "Cultural competence changes in scope and depth over time based on individual and group experiences of cultural diversity, awareness or knowledge of ways in which groups and individuals are similar and distinct from one another, sensitivity or open attitudes toward self and others, and the acquisition and practice of skills" (p.257).

\section{Background}

Our two disciplines, the School of Nursing and the School of Business and Economics came to together to explore ways that we could raise our students' awareness of cultural influences within communication beyond a textbook and create a more experiential learning project, using the campus environment as a living lab. As instructors, we recognized our objectives in the course and fuller program included a mutual appreciation of culture and a need to have skills to better communicate and understand 'others'. Both programs of learning include dealing with a diverse population regionally and globally, requiring skills to understanding the importance of social etiquette and political and cultural influences in social interactions.

We recognized that both of our degree student groups, Bachelor of Business and Baccalaureate of Science in Nursing had common knowledge interests for skill development that would enhance inter-cultural communication and interdisciplinary communication; thus broadening their understanding of communication practices. We used Thompson Rivers University's (TRU) diverse student cultures and academic diversity as an opportunity for experiential and interdisciplinary student learning. In light of TRU's multidisciplinary features and the range of international students on campus, it was realized this assignment offered a very good opportunity for an experiential communication exercise and to explore a way to create greater student engagement with theoretical concepts. 


\section{Literature Review}

The post-secondary learning environment strives to be inclusive and challenges educators to find ways to demonstrate cultural diversity -without having to travel- rather taking advantage of the living lab of different cultures on campus. International students have an added challenge to integrate with students in host country to maximize their intercultural experiences (Peacock \& Harrison, 2009; Sovic, 2009). Summers and Volet (2008) believe there is an ideal social forum for enhancing intercultural competence for all students on campus. Culturally mixed group assignments, are viewed as an effective way to enhance host and international student intercultural components. Denson and Zhang (2010) found that diverse student group projects influence a student's respect for difference and enhances one's team-work skills and problem solving. Home students have been found to not always challenge their awareness of language and cultural point of view by voluntarily interacting with international students (Harrison \& Peacock, 2009); voluntary interdisciplinary interaction is also rare, as most students focus on their discipline unless facilitated otherwise. Strauss and Young (2011) postulate that this reluctance to interact with other cultural identities beyond a surface level in post-secondary education may be due to diversions of academic goals and simply an avoidance to uncertain academic stress.

Engagement of learning happens mostly outside the classroom where experiential learning allows students to work through processes (Pascarella \& Terenzini, 2005); however, this is more likely to happen with homogenous groups (Strauss \& Young, 2011). Brown (2009) argues the challenge for multicultural campuses is to increase greater social cohesion, on campus and globally, through extensions of cross-cultural contact, transforming higher education students into inter-cultural mediators, having raised awareness beyond their own culture. With facilitated or intentional learning activities, such experiential learning is possible with cross-disciplinary and intercultural student groups. By doing so, educators bypass the unchallenged conceptions that most often isolate diverse students (Ippolito, 2007). Knowledge of cultural attitude and intercultural competence transformation could occur during an interdisciplinary group project during the planning of the meetings, while working through communication dynamics, while explaining individual rationales to others for completing assignments, and while working through language barriers and cultural beliefs when attending to the learning activity itself.

Jyakakumar (2008) supports cross-racial interaction, through intergroup learning, is a powerful opportunity to understand another perspective, enhance leadership skills incorporating cultural awareness and understanding, and creates a space to think about one's own social identity. Jyakakuma (2008) asserts that universities are responsible for producing cross-culturally competent citizens. The workforce is full of different worldviews, negotiating multiple cultural perspectives. Higher education is the ideal place for accomplishing a diverse experience and global citizenship. Campus environments offer a unique circumstance, where students can engage outside of their "racially homogenous friendship circles" (Antonio, 2001, p. 612).

Exposure to diversity on campus is of mutual importance to the nursing education field and business education field, as graduating students will find themselves associated with diverse interpersonal communication challenges, diverse global beliefs and ever changing intercultural workplace systems throughout their careers. Benarz, Schim and Doorenbos (2010) postulate that nursing schools desire to become more diverse to benefit the population graduating nurses will care for while appreciating differences between the cultural, ethnic, and religious traditions carried by each individual nurse in their role as a caregiver. Additionally, nursing culture includes cross-cultural 
elements of communication, through a professional language and jargon that challenges relational practice building. The challenge for teachers would be to work through strategies with students on how to work with a diverse population, addressing the human nature of working with cultural difference. Cross-cultural competency development is a crucial element to be facilitated while in the higher education arena.

\section{Description of Learning Activity}

\section{Goals of Activity}

The goal of the activity is to gain experience is engaging with other cultures and to consider different perspectives of other cultures. Representing at least 2 students from each discipline, students met mutual and specific learning goals that were threaded into their course specific assignment outcomes. Before the groups met to conduct a reciprocal interview based on the semi-focused questions from the learning assignment, they had to complete a Group Charter (See Appendix A). The group charter was used as a method to better understand the member's hared expectations, and goals for group activities. This tool of group conflict management, assisted with bringing the cohort and non-cohort dynamics together in a mutual way.

As the interviews progressed, both student disciplines had a paper assignment based on the interaction and information they gathered from each other, worth $25 \%$ of their total grade (See Appendix B).

For nursing students, a specific goal was to provide them with the opportunity to organize, prioritize, and practice conducting face to face interviews with someone from a different culture, whether the culture represented a discipline, ethnicity or otherwise. In the profession of nursing, the definition of culture is often utilized from nursing colleagues. Doane and Varcoe (2015) state that culture can be viewed as, "a dynamic relational process of selectively responding to and integrating particular historical, social, political, economic, physical, and linguistic structures and processes" (p.139). While considering this definition of culture nursing students were encouraged to view culture as a way of how other experience life differently. This allowed nursing students to reciprocally share their understanding of healthcare differences and practice differences in relating to others with the business students.

The international business students, while sharing their understanding of the same practices, came with a more business lens, exploring different in ways the health care industry is managed internationally. Each student compared the extent their own home country health care industry including the notion of publicly or privately operated health care. All students learned to broaden their awareness and knowledge of different national political orientations towards this industry.

For example, comparing the relatively publicly managed Canadian healthcare system, with an increasingly commercialized and privatized system in China and Saudi Arabia, offers the opportunity for students to see these practical differences and the implications for both versions on the domestic population. While the discussions and exploration took place, the students were also exploring social etiquette and nuances needed to acquire the information as well as have a respectful conversation.

\section{Instructor Preparation}

In order to conduct an interdisciplinary group project we need to be organized with names in groups before the course began, with an even mix of cohort versus non-cohort (nurse student versus 
business student) in predestined groups to avoid any confusion. The educators met and tried to coordinate the names within the same sections to create more familiarity and comfort within the group. Additionally, the instructions for the project were written similarly between both disciplines, and the instructions to the students with ESL (English as a Second Language) were given verbally and with extra attention for validation of the expectations. The groups were kept to 5 or less for the purposes of decreased issues with scheduling (not too big) and for the less faculty work load (not too many).

The International Business instructor needed to arrange students in three classes by different nationalities. This was accomplished by the instructor polling the students to determine which country they most identified with such as their place of birth. With this country of birth information, the instructor then set-up an Excel spreadsheet that first organized students by their county of birth, and then set up groups that represented individuals from at least two different countries. This ensured that each group had individuals from at least two different nationalities, so diversity would be richer for all parties, especially when discussing the politics and economics of different healthcare systems. The instructor ensured the groups were comprised of individuals from the same section (or class) of International Business. This enabled some "in-class" time for this assignment to be worked on by the international business students, especially if ESL was a factor. Next, the instructor allocated two nursing students to each of the International Business groups.

For instructor consideration, the School of Business had the assignment as a group paper and for the School of Nursing; the educators had an individual paper or group paper option. The due dates for the assignments were within the same week for all disciplines, the interview dates were to start at the same week for all groups. Each group was expected to meet at least twice.

\section{Learning Activity Implementation}

\section{Intercultural Concepts Introduced}

On the day the intercultural groups were announced to the students, discussions on culture, cultural sensitivity, and group charter principles were covered by each educator. For business students a lecture on different cultural communication characteristics was given by the University Intercultural Expert, Dr. Kyra Garson. Discussion regarding culture not being confused with race, ethnicity, or nationality was ongoing. Rather cultural was treated as related to multiple influences that shape a person.

\section{Exercise Introduction}

The exercise and assignment requirements were discussed and in writing for all of the students. Additionally, the students were informed by the educators that the questions were in a semi-formal format as guidance to create an open conversation. The questions were delivered ahead of time and class time was allotted to discuss the content and any concerns. All students were advised to contact their educator at any time during the course of the interviews and assignment, with any concerns, questions, or comments. Moreover, confidentiality, respect, conveyed in the classroom through teacher facilitated discussion for the protection and commitment to the group relationship. Mutual respect for other's ideas, flow of communication, and tools to address conflict using the Group Charter were included in discussions during class time before heading out into the interview. 


\section{Exercise Ogoing Support}

As faculty, we realized that group dynamic challenges would possibly occur and kept open and available office hours, email contact, and open feedback discussions throughout the course. As diverse educators ourselves, we continually communicated the progress of our separate disciplines and worked proactively to make the experience as successful as possible. We found students were very creative with problem solving and using various techniques to communicate with language barriers. As faculty, we encouraged them to use share their resources amongst their peers. Again, this provided rich learning throughout the semester.

\section{Student Groups}

Ultimately, students were assigned intercultural and interdisciplinary groups. Each of these groups had 5 students, including: two School of Nursing Students and three International Business Students. Although these groups were larger than both instructors would have preferred, these groups where designed to ensure that all nursing students were included in the diverse groups and each group contained a culturally diverse mix. The differing dynamics and structure of the two different disciplines are worth noting and greatly affect the setting up and process of the learning. The students in the International Business (IBus 3510) course at TRU are enrolled in the School of Business and Economics degree program. This is a third year course made up of three different sections and not in a cohort environment. These students autonomously select their classes, class times, and instructors with a class size approximately 40 students. As with most University students, there is a wide-ranging of student engagement and commitment within the School of Business and Economics. In broad terms the student composition of these sections is approximately $25-30 \%$ domestic Canadian with the remaining approximate $75 \%$ being from India, China, Saudi Arabia.

Due to the "non-cohort" nature of the School of Business and Economics, students may not have the opportunity, or need, to interact and to develop friendships with students from other disciplines and cultures. On the other hand, the School of Nursing (SON) BScN program, is made of a cohort of 80 students per year level, with students taking nearly all of their courses together have aligning assignment schedules. $90 \%$ of the SON is female with the majority domestic to Canada.

\section{Teaching Challenges Conducting the Learning Activity}

There were a number of challenges for teachers when setting up this activity, mostly regarding the initial contact by the various group members. One challenge was effectively sharing students contact information without infringing on their privacy. In particular, instructors did not want to share personal emails with other students. Eventually, the use of the University assigned email address was used. Unfortunately, not all students regularly read messages sent to this email account.

\section{Non-Cohort Student Challenges}

Most of the students enjoyed the process of meeting with other discipline students. However, scheduling continually becomes a challenge, especially for those that had present cohort obligations, such as the nursing students. Nursing students are assigned at least two days a week off campus doing clinical rotation duties. Other challenges with scheduling interviews included the inability to meet due to family obligations, work obligations, and evening course times for business students. The scheduling and time management challenge definitely reflected the most visible differences between a cohort and non-cohort structure. Another challenge was the lack of preenrollment information and last minute drop outs in the non-cohort group This meant waiting at 
least three weeks into the course to assign members to a group; creating some anxiety with the cohort discipline. Of note, a characteristic of the IBus classes is an approximate dropout rate of $5 \%$ over the semester. Due to this phenomenon, the business instructor did have control over changes to the groups during the semester.

\section{International Student Challenges}

Faculties facilitating this type of assignment need to be aware of the power dynamics and cultural barriers within the groups working together. The cultural diversity within the international business students posed some challenges during the group learning assignment, as language barriers, cultural expectations and gender expectations sometimes made student meetings strained. Some international students struggled with the main campus language being English, and the written assignment in English. At times domestic students in the business program complained that they had to take on the assignment writing on behalf the ESL student. As well, some nursing students were concerned that the domestic business student took over the conversation blocking the international student from talking and at the same time offered assumed interpretation of what the ESL student might have wanted to answer. As a result, several groups reported meeting second and third times without the more domineering domestic business student to glean from the international student's perspective more first hand.

\section{Assignment Debrief}

\section{Evidence of Effectiveness}

Both of the groups gave positive informal feedback on the experience of meeting other students on campus outside their discipline. Both nursing and business students stated, "I would not normally have met someone outside my program or approached an international student", "this forced me to meet others outside my comfort zone and it was an excellent experience", or "I enjoyed meeting someone new, I have not talked to a Canadian student yet, I most likely would have not if we didn't do this activity" and "meeting international students and those in a different program really tested my prejudice...I really needed this experience".

\section{Listening and Observing Students}

Discussions in the classroom and individual feedback on both courses included similar themes of surprise over the experience of the interview, such as what was learned about individual cultural perspectives on social etiquette and health care expectations, how communication can be present differently when English is not a first language. Additionally, students in both groups learned how the concept of time is or is not different priority for different cultures. The majority of the students from both departments stated or wrote that they liked the assignment and would do it again. Student expressed appreciation for the assignment and found new knowledge on different cultural perspectives. The activity had a theme of 'fun' and 'seriousness'. For groups that had scheduling difficulties, general feedback continued to be good although all wanted to have the assignment start earlier in the semester. As one nursing student stated, "It takes time to gain trust to answer and discuss some of the questions."

\section{What did the assignment teach students?}

A number of observations were made by instructors over the course of the semester about student behavior, which can be attributed to this assignment. Additionally, students voluntarily gave verbal 
and written feedback on an end of course survey specifically targeted toward the assignment. The following themes were discovered.

\section{Communication with Cultural Sensitivity}

The majority of the students taking part in this assignment made new knowledge discoveries of other cultural, individual, and ethnic backgrounds on topics of healthcare, business, politics and social etiquette. Generally $81 \%$ of nursing students found increased awareness of communicating and interacting with others through a nursing lens, while $70 \%$ of the business students found new perspectives and information regarding individual understandings of public and private healthcare practices. While gaining new knowledge, the students learned new ways to communicate with others and reflected on their previous views of such. Additionally, feedback from the student experience included several acknowledgements on time management skill development regarding the interview scheduling, as well as creative ways to meet each other.

The rich learning described in their individual or group written assignments included themes of being patient in communicating with those having language difference, keeping an open mind regarding personal perspective, taking extra steps to research other cultures to confirm or critique answers from group members, developing friendships across cultures and discipline during and after the course, and general positive comments regarding the idea of meeting strangers with semifocused questions to break the ice and have several conversations, each getting deeper in detail and more comfortable as trust built over time. $66 \%$ of the nursing students answering the end of course survey on the assignment found the assignment beneficial to increasing their knowledge of diversity on campus, those that answered 'no' gave such explanations: "I have already immersed into the population on campus", "I view healthcare as diverse already, but found individual perspectives in the meetings to be beneficial in testing my own personal bias", "I have travelled a great deal, have interracial friends all my life and have been on campus long enough to understand there is diversity here and in the working world" and reflected, "to be a nurse, you must accept diversity exists" and "not really, the trick is discovering ways to communicate differently and effectively that counts, so keep using this assignment."

\section{Problem Solving as Team Player}

The assignment involved a diverse and busy group of students and there were cross cultural group dynamic challenges. Some group members found they had to plan meetings creatively and problem solve ways to fairly distribute the written work, most using the charter tool at the beginning of the assignment constructively. On the end of course survey, $75 \%$ of the business students agreed the group charter was beneficial to the group's ability and willingness to cooperate. Specifically, the group charter was used at the beginning of the process as a tool to be proactive in scheduling meetings and attend to conflict between workload tension and differing views on assignment expectations. Some students requested the tool be discussed more formally in the beginning of the course, as there were some misunderstandings of the relevance, specifically from the business students. This gave insight to the educators from both disciplines to spend more time on validating student understanding of the group charter tool.

\section{Building Intercultural Confidence}

This activity provided the motivation for students from different cultures and disciplines to meet and talk about how their lives are different and similar. To this extent this assignment offered an opportunity for students to gain intercultural awareness and knowledge through direct experience 
and personal interaction. One of the most rewarding aspects has been how the assignment has brought students out of their "cultural ghettos". This was especially noticeable later in the semester. The instructors witness and heard stories how individuals genuinely found ways to introduce their culture to their other group members. For example, several students brought pictures of their families, shared family food recipes, and discussed their political and ethical concerns regarding business and healthcare practices from home countries both Canada and beyond.

For business students, this assignment also offered the opportunity for interdisciplinary knowledge, in particular, to become more aware of the health care as an industry and whether it is publicly or privately managed. For the nursing students, this assignment offered additional communication practice and further skill development of working through personal assumptions of other cultural understandings and empathy development. A number of results drawn from student feedback completed post assignment support the success of this assignment. In particular, $90 \%$ of business students and $83 \%$ of nursing students stated the assignment successfully increase their knowledge of other cultures.

Nursing students quotes from the end-of-course survey included: "I was able to dismiss biases and stereotypes I unfortunately had before and I was able to meet people I never would have without this opportunity", "It took me outside of my comfort zone, I didn't' have my instructor or a nurse to hold my hand as I went to meet complete strangers" and "I had a chance to openly discuss "random" question and driven questions I would not have felt comfortable asking an international student outside this context. I have more confidence now" "I have an absolute better understanding of other programs and situations other cultures go through while away from home and also got a chance to practice using my communication skills in a safe way", "I learned so much more than I would've expected, not just about different cultural practices, but also the truths and falsehood of stereotypes. I just wasn't' aware about some of the small differences in cultural practices, and now I find myself more conscious of these differences."

International business student quotes from the end-of course survey included: "Yes, before the assignment, I didn't know much about Saudi Arabia. Now, I know it is quite the same in a lot of aspects to China. And I learned that family members get along with each other in Canada. Helpful!", "I learned a lot about the two other cultures. Hearing the perspectives from people that have lived it, really gives a greater understanding", "The analysis required for the points we needed to discuss for this project were relevant to us to the perception we had about each country. It also broke the stereotypes we had", "It made me learn other aspects of the culture than stereotypes. It also gave me a better understanding as it came from an actual person, and not more generalizations", "By completing this project, I had a better understanding of different culture in Canada, India, and China. I think it's helpful to my major, especially for business" "Understand the economic policy about Canada, and make friends with each other" and "For me as an international student it was really interesting to get to know Canada a bit better and learn from different perspectives."

\section{Conclusion}

\section{Future projects}

Based on experiences with this assignment, a number of adjustments have already been made and others will continue to be made to improve the students learning experiences. This is an evolving experimental assignment guided by the student performance and strongly related to learning response. The first significant adjustments were introduced during the second running of 
this assignment which included the use of the team charter. The introduction of the Team Charter and the requirement of completion and submission within two weeks have proven to be a positive change to this assignment. This has ensured the group members meet at least once early in the semester as it has given students the opportunity to discuss their group expectations and share communication information.

\section{Educator Reflections}

Transparency and clarity are paramount for the success of this assignment; instructors have more closely aligned their assignment questions and percentage marks across both disciplines, to assist with leveling equal investment in the academic energy going into the assignment. The educators recognize that ongoing support for students and ongoing communication needed between instructors is essential in pulling off the multi-dynamic assignment. Dr. Kyra Garson, our intercultural expert and consultant on campus, has observed that in some cases forcing intercultural groups together can serve as a further instill of negative perception of another culture. For the sake of pragmatics operation the groups will continue to be predestined by the educators but the consistent alignment of course objectives, assignment requirements, due dates, topic questions, and the group charter will be observed. The instructors are working on using a case study example for the students to work with to enhance individual perspective of business and healthcare utilizing the current consideration of the privatization of the British Columbia ambulance service.

\section{APPENDIX A}

\section{Intercultural Literacy Group CHARTER}

\section{Introduction:}

Groups work better when members have a common understanding of the group's shared expectations, and goals for group activities. Each member of your group will have some idea how the group should operate. This is the opportunity to share your thoughts so "simple misunderstandings" are less likely to arise in the future. The purpose of this Charter is therefore to help your group set some of these ground rules and goals.

\section{Instructions:}

Please make sure your answers are clearly stated. Also, it is important your Charter is agreed upon by everyone in your group.

- $\quad$ As a group (IB students and Nursing students), please complete the questions involved in this Group Charter.

- $\quad$ Appoint one member of your group to make a photocopy of this charter and give it to your instructor at the requested time.

\section{Our group's name (optional):}

What will be the name of your group?

\section{Our ground rules:}

- $\quad$ On average, how long should our meetings be?

- Where will our meetings take place? 
- When is it OK to miss a meeting?

- $\quad$ How do we inform each other when we can't be there or are running late?

- $\quad$ How will we deal with lateness to meetings?

- What does "on time" mean?

- What do we do with mobile phone calls \& text messaging during meetings?

- $\quad$ Can we bring food and drink to meetings?

- How do we deal with members who don't participate enough, participate too much or distract the group from its task?

- $\quad$ How are we going to make decisions?

\section{Our goals}

- What is our group trying to accomplish? Aimed \% grade for the project?

- $\quad$ The team charter should also include:

- Timeline for work to be completed

- Conflict resolution- steps/process \& consequences of unacceptable behavior and performance.

\section{Our commitment to the charter:}

- We agree with the answers in our charter and will try our best to uphold them.

Printed Name: Contact information Signature: Date:

\section{APPENDIX B}

\section{NURS2170 Reflection Essay on Communication and Culture Interview (25\%):}

The purpose of this paper is to demonstrate the nurse learner's understanding of how to connect with others from a different culture and reflect on ways to build a trusting and caring relationship through a professional lens.

By the 5th week of class you will have met a TRU student from the School of Business in a mutually agreed upon place to share communication information comparing your and their cultural verbal and non-verbal mannerisms. The School of Business students will also have a learning activity to follow from their course work related to International Business. Their answers will remain 
anonymous, with no name attached. Please make sure the student knows this. Though this visit with another university student you are to inquire about the following questions:

1) What mannerisms are acceptable and unacceptable to the student and what influences the student to think this way (i.e. what cultural background to they describe themselves from)?

2) If you were to visit the student's home for dinner what social etiquette or behaviors should you use to fit in?

3) What behaviors does the student think you might have a hard time doing if meeting their family?

4) What social etiquette examples would the student expect if you were their family member's nurse? Does this change with gender difference?

5) What Canadian behaviors or manners does the student find hard to accept and why?

After your meeting with this student you are to write up the answers and give them and Dr. Fehr a copy (with your essay). Do not identify the student by their real name (keep their identity anonymous). When sending the answers to the student, ask for validation on the answers. Did you understand their answers correctly? This is a way to test your ability to accept feedback and also seek genuine feedback (just as we would with our nurse-client relationships). The School of Business students are expected to validate your response. Attach your findings and their response as Appendix A: TRU Student Interview to your Essay.

Break your essay into two sections: 1) The interview process and 2) Your reflection about culture and communication

Section One: In your essay discuss the following regarding the TRU student interaction.

1) Describe the interaction process, how did it go?

2) What communication did you and the student use to build trust to answer the learning activity questions?

3) Did you have any challenges during the inquiry, if so what were they?

4) What were your preconceived ideas before the meeting the TRU Student and how where these ideas different after the meeting?

5) Give a description of a cultural group the person you met from the School of Nursing may represent and imagine caring for them in your nursing practice.

Section Two: Imagine being this student's nurse and the cultural group they stated to represent. Identify your use of gray references versus evidence-based practice references as you answer the following questions.

1) What are the challenges this cultural group may have with the Canadian health care system? Why do you think this way?

2) What challenges may you have when caring for this cultural group? Why do you think this way?

3) What tensions may exist within this cultural group's family unit within the Canadian health care system? Why do you think this way? 
4) How, through your ability to communicate with a professional lens, can you create a more effective health-promoting relationship with a person from this cultural group?

Each section of the paper should be 4-5 pages long, double spaced, in APA format, and have a minimum of 3 peer reviewed references (attached) within the last 5 years. As well, attach an appendix with the interview answers and feedback (leaving out the student's name). A total of $10 \%$ will be deducted for each day the paper is tardy...including weekends.

\section{Papers will be graded as follows:}

1. Clearly completed Appendix A, Section 1 and Section 2 and cultural considerations

\section{References}

ALLEN, J. (2010) Improving Cross-Cultural Care and Antiracism in Nursing Education: A Literature Review. Nurse Education Today. 2010, Vol.30, No.4, p. 314-320. https://doi.org/10.1016/j.nedt.2009.08.007

BEDNARZ, H., SCHIM, S., and DOORENBOS, A. (2010) Cultural Diversity in Nursing Education: Perils, Pitfalls, and Pearls. Journal of Nursing Education. 2010, Vol. 49, No.5, p. 253-260. https://doi.org/10.3928/01484834-20100115-02

BROWN, L. (2009) A Failure of Communication on the Cross-Cultural Campus. Journal of Studies in International Education. 2009, Vol. 13, No. 4, p. 439-454. https://doi.org/10.1177/1028315309331913

DENSON, N., and ZHANG, S. (2010) The Impact of Student Experiences with Diversity on Developing Graduate Attributes. Studies in Higher Education. 2010, Vol. 35, p. 529-543. https://doi.org/10.1080/03075070903222658

HARRISON, N, and PEACOCK, N. (2009) Cultural Distance, Mindfulness and Passive Xenophobia: Using Integrated Threat Theory to Explore Home Higher Education Students' Perspectives on 
"Internationalisation at Home". British Educational Research Journal. 2009, Vol. 36, p. 877-902. https://doi.org/10.1080/01411920903191047

HOU, J., and MCDOWELL, J. (2013) Learning Together? Experiences on a China-U.K.

Articulation Program in Engineering. Journal of Studies in International Education. 2013, Vol. 18, No.3, p. 223-240.

IPPOLITO, K. (2007) Promoting Intercultural Learning in a Multicultural University: Ideals andRealities. Teaching in Higher Education. 2007, Vol.12, p.749-763. https://doi.org/10.1080/13562510701596356

JAYAKUMAR, U.M. (2008) Can Higher Education Meet the Needs of an Increasingly Diverse and Global Society? Campus Diversity and Cross-Cultural Workforce Competencies.

Harvard Educational Review. 2008, Vol. 78, No.4, p. 615-651. https://doi.org/10.17763/haer.78.4.b60031p350276699

PASCARELLA, E and TERENZINI, P. (2005) How college affects students: A third decade of research (2 ${ }^{\text {nd }}$ ed.). San Francisco: Jossey-Bass. 2005.

SOVIC. S. (2009) Hi-Bye Friends and the Herd Instinct: International and Home Students in the Creative Arts. Higher Education, 2009, Vol. 58, p. 747-761. https://doi.org/10.1007/s10734-009-9223-z

STRAUSS, P., and YOUNG, S. (2011) "I Know the Type of People I Work Well With": Student Anxiety in Multicultural Group Projects. Studies in Higher Education, 2011, Vol.36, p. 815-829. https://doi.org/10.1080/03075079.2010.488720

SUMMERS, M., and VOLET, S. (2008) Students' Attitudes Towards Culturally Mixed Groups on International Campuses: Impact of Participation in Diverse and Non-Diverse groups. Studies in Higher Education, 2008, Vol. 33, p. 357-370. https://doi.org/10.1080/03075070802211430 